\title{
IMPACTO DEL MUNDO DIGITAL SOBRE LAS REPRESENTACIONES GRÁFICAS DEL DISEÑO ARQUITECTÓNICO LA EXPERIENCIA 2014 EN EL TALLER UIRTUAL DE ARQUITECTURA IU, UPC
}

Alejandra S. BIANCHI (1) / Gustavo A. TRIPALDI (2) / Gladis E. PINTOS (3) / José R. ITURRIAGA (4) / Sergio D. VARGAS (5)

1. Profesora titular, dedicación exclusiva, Sistemas de Representación y Expresión, FAU-UNNE / 2. Profesor adjunto, dedicación exclusiva, Arquitectura IV, UPC, FAU-UNNE / 3. Jefa de trabajos prácticos, dedicación exclusiva, Arquitectura IV, UPC, FAU-UNNE / 4. Jefe de trabajos prácticos, dedicación exclusiva, Arquitectura IV, UPC, FAU-UNNE / 5. Auxiliar docente de primera, dedicación semiexclusiva, Arquitectura IV, UPC, FAU-UNNE.

Palabras Clave: Representación gráfica; diseño arquitectónico; taller virtual.

Keywords: graphic representation; architectural design; virtual workshop

\section{RESUMEN}

Este trabajo expone los resultados preliminares del Proyecto de Investigación 12C006-2013-16 "Las Representaciones Gráficas en la formación de alumnos de la carrera de Arquitectura-UNNE". Se busca expresar el impacto del mundo digital sobre las representaciones y conocer las habilidades y destrezas del estudiante en relación con los sistemas de representación a través de cortes transversales en cinco momentos de la carrera de Arquitectura (nivel ingresantes, primero, segundo, cuarto y sexto años). A través de una investigación cualitativa, descriptiva-explicativa, nos explayamos en el taller Virtual Red Norte Grande, experiencia innovadora única de taller colaborativo en la cátedra Arquitectura IV, UPC.

\begin{abstract}
This paper presents the preliminary results of the Research Project 12C006-201316 "Graphic Representations in training in the career of Architecture-UNNE". It seeks to express the impact of the digital world on representations and to know the skills of the student in connection with representation systems through transects in five moments of the career of Architecture (beginners level, first, second, fourth and sixth years). Through a qualitative, descriptive-explanatory research, we expand on Red Norte Grande Virtual workshop unique collaborative workshop innovative experience in the chair Architecture IV, UPC.
\end{abstract}




\section{OBJETIVOS}

Se busca contribuir a reformular y producir nuevas estrategias pedagógicas en el proceso de enseñanza-aprendizaje de la representación en el diseño arquitectónico en la carrera de Arquitectura, para lograr aprendizajes significativos en los alumnos, durante su formación en la carrera de Arquitectura de la UNNE.

\section{DESARROLLO}

El presente trabajo se enmarca dentro del Proyecto de Investigación 12C006-2013-16 "Las Representaciones Gráficas en la formación de alumnos de la carrera de Arquitectura-UNNE", que estamos desarrollando para conocer la manera en que los alumnos de arquitectura de nuestra universidad representan el objeto arquitectónico con métodos analógicos y digitales en la actualidad.

Los alumnos realizan la construcción de sus conocimientos en diseño arquitectónico estructurando sus esquemas mediante conocimientos, actitudes y utilizando herramientas para el diseño en un mundo digital. El marco teórico de la investigación se basa en la teoría de LAWRENCE STENHOUSE, que expresa: "los profesores tienen un papel activo en la investigación de la enseñanza. Mejor que hacer efectivas las ideas de investigadores externos, que sea el profesor el que investigue su propia practica y valore su situación de una manera crítica".?

Cátedra Arquitectura IV, UPC: en el taller de Arquitectura, se desarrolla un proceso pedagógico en el cual alumnos y docentes desafían en conjunto temas-problemas específicos del hacer proyectual; es así que se convierte en la actividad troncal del currículum de la carrera. Se trata de que las ideas surjan de contemplar las necesidades y las técnicas de materialización, y para ello en Arquitectura IV se establecen fases o etapas del proceso proyectual, que permiten a los alumnos avanzar conscientemente, desde la elaboración crítica de la alternativa de pre-partidos posibles, hasta el partido y su verificación en el anteproyecto. Los docentes aportan como tutores guías y desarrollan un rol como tutores virtuales y coordinadores de las actividades dentro de la experiencia Taller Virtual Red Norte Grande (que combina la modalidad de educación a distancia con la presencial), lo que distingue con valor diferencial la propuesta pedagógica de la cátedra Arquitectura IV.

Los docentes desarrollan sus actividades dentro de esta experiencia innovadora (Taller Virtual Red Norte Grande) vinculando y articulando el proyecto de docencia con el de investigación en curso, íntimamente relacionados, a fin de retroalimentar la actividad del taller aportando desde la investigación a la práctica docente. Esta experiencia del Taller Virtual Red Norte Grande se sustenta en la certeza de que mediante la constitución de redes las instituciones de educación superior podrán unir y compartir el potencial científico y cultural que poseen.

Es de destacar que el Taller Virtual Red Norte Grande aborda con énfasis la necesidad de establecer vínculos, articulaciones y redes de cara a los procesos de integración regional, de modo de instalar el intercambio de experiencias, el desarrollo de prácticas conjuntas y el uso de las nuevas tecnologías (en este caso en el proceso enseñanza-aprendizaje de la arquitectura), tal como se alienta en los lineamientos de Arquisur (Asociación de Escuelas y Facultades Públicas de Arquitectura del Mercosur).

1 Stenhouse Lawrence, La Investigación como base de la Enseñanza. 
"La tecnología aplicada a la arquitectura permite encontrar otra forma de pensar en ella, sin que esto origine un nuevo estilo, sino definitivamente una nueva forma de crear, pensar, dialogar, comunicar."

Como expresa FRANCISCO MARTÍNEZ MINDEGUÍA, "Representar con eficacia, en medio de la explosión de recursos que brindan los sistemas informáticos, exige un constante ejercicio de rigor y selección consciente e intencionada. Algo que requiere gran claridad conceptual. Los sistemas lingüísticos y los sistemas de representación han cambiado rotundamente y en muy poco tiempo... Y, lógicamente, la profesión del arquitecto no ha tenido capacidad ni tiempo material para asimilar ese cambio. Hoy, el ámbito de la representación arquitectónica profesional es un terreno de confusión"2.

En este contexto los docentes de la cátedra Arquitectura IV han avanzado en una investigación descriptiva-explicativa sobre las maneras en que los alumnos de Arquitectura de la FAU-UNNE representan las imágenes arquitectónicas con métodos analógicos y digitales en la actualidad. Para ello, se realizó una evaluación diagnóstica de lo trabajado en 2014, a fin de contribuir a la producción de nuevas estrategias pedagógicas en el proceso de formación y ajustar la planificación de las cátedras y áreas involucradas.

Los principales propósitos que guiaron la investigación fueron identificar y conocer las distintas maneras en que los alumnos prefiguran y construyen sus imágenes arquitectónicas; verificar y sistematizar los modos y las herramientas con que los alumnos configuran las imágenes arquitectónicas, a través de un seguimiento pormenorizado de grupos de alumnos en el nivel de taller de cuarto año de la carrera de Arquitectura y analizar el impacto del mundo digital en la construcción de las representaciones gráficas de los alumnos, fundamentalmente en cada etapa del proceso proyectual. Dicho diagnóstico 2014 implicó seguimiento fotográfico-digital y análisis de documentación de croquis, plantas,

$2 \mathrm{http}: / /$ mindeguia.com/congresos/3IAU_M5_13.pdf cortes, vistas, perspectivas polares, axonometrías y maquetas, realizados con medios analógicos y digitales, en dos y tres dimensiones. Esta información ha sido procesada conforme a variables tales como conocimientos conceptuales, grado de síntesis, capacidad de comprender y comunicar a través de la gráfica, manejo de las proporciones y destreza para la representación en sus diferentes variantes, manejo de herramientas digitales para expresar ideas durante el proceso de diseño y el uso de la tecnología, que posibilita la interacción en una red virtual.

Cabe a aclarar que en el ciclo TVRNG 2014, se trabajó en la ciudad de San Miguel de Tucumán para la realización del trabajo denominado Tucumán, fábrica de cultura, "Las Cúpulas". Participaron en esta experiencia virtual / académica las cátedras de Arquitectura 4 UPC de la Facultad de Arquitectura y Urbanismos de la UNNE y la cátedra Arquitectura 4 / Combes de la Facultad de Arquitectura y Urbanismo de la Universidad Nacional de Tucumán. Los trabajos se desarrollaron con grupos en cuatro comisiones.

\section{Comisión arquitecto José Iturriaga}

Entendemos al lenguaje gráfico como la expresión natural del arquitecto, por lo que conocer el potencial de las herramientas digitales y su aplicación directa en la visualización de arquitectura es imprescindible para no sentirnos limitados y condicionados y que nuestras ideas nazcan y se expresen libremente, moldeadas únicamente por aspectos proyectuales.

La tecnología aplicada a la arquitectura permite encontrar otra forma de pensar en ella, sin que esto origine un nuevo estilo, sino definitivamente una nueva forma de crear, pensar, dialogar, comunicar. No nos alejamos con esto de lo planteado en el movimiento moderno y su concepto acerca de la 


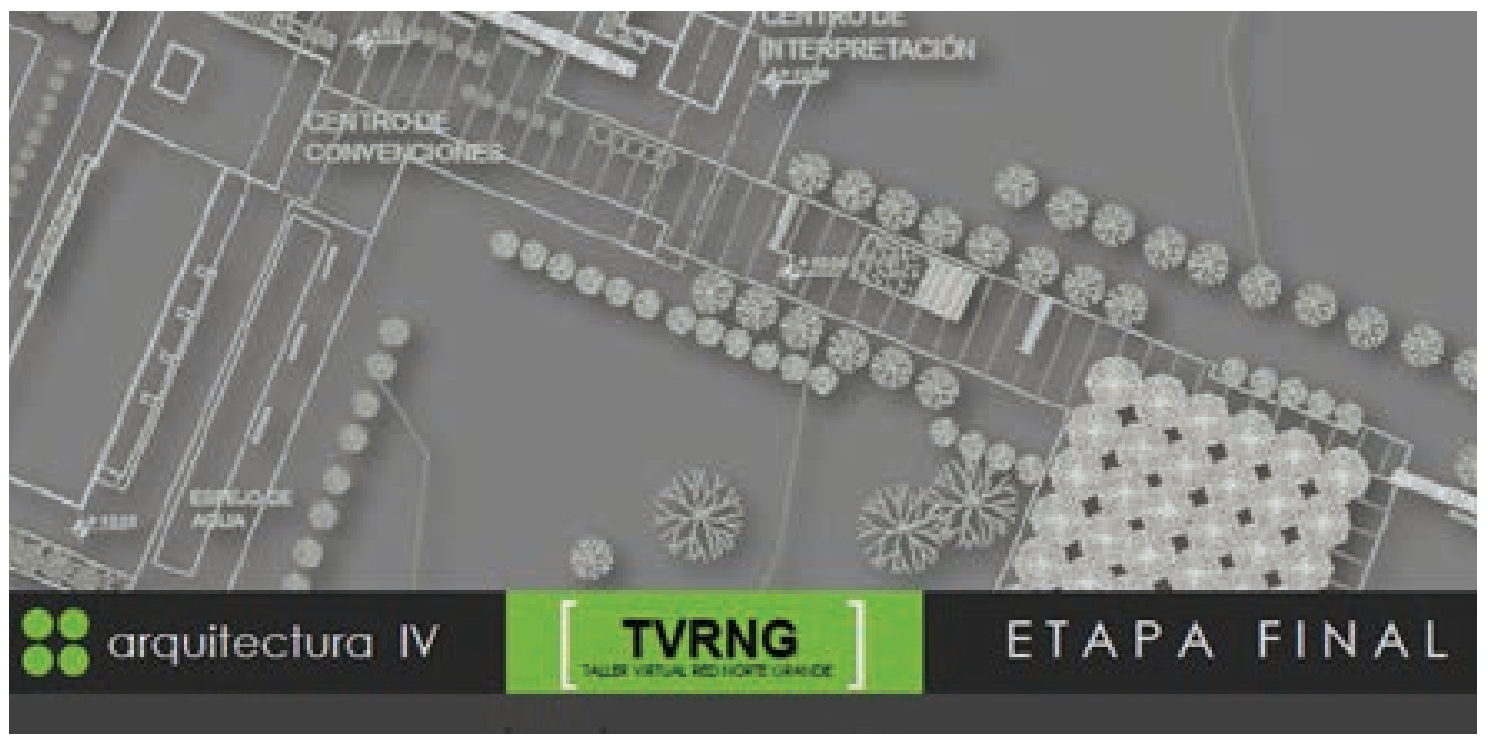

arquitectura, pero es inevitable pensar en una nueva génesis del acto creativo considerando las variables que permiten los diferentes programas de diseño y su combinación con los métodos tradicionales. La computadora facilita la experimentación formal, y utilizada en el momento preciso y bajo condiciones controladas y definidas en el proceso de diseño permite definir y comunicar eficazmente una idea. Esto implica un cambio de paradigmas que modifican los conceptos de la arquitectura tal cual la conocemos ahora.

Todo este proceso de incorporación de la tecnología digital en la ideación tiene que ir necesariamente acompañado de un manejo consciente por parte del alumno o diseñador de los diferentes medios de comunicación, desde el boceto inicial a mano de una primera idea, del uso de la maqueta y del relato gráfico combinados y enriquecidos por la infinidad de posibilidades que los programas digitales facilitan.

El desafío planteado por los docentes de la cátedra en sus diferentes comisiones se centró en incentivar a los alumnos en la experimentación de esos medios digitales y tradicionales buscando la reflexión de su uso en cada etapa del proceso de diseño. Este camino propuesto lleva al alumno a buscar el medio más cómodo de expresar sus ideas dentro de los objetivos expresamente definidos en las guías y clases teóricas de cada etapa, de acuerdo con el nivel acordado para un alumno de cuarto año de la carrera de arquitectura. El ejercicio se complementó y enriqueció con el trabajo en red propuesto en el segundo cuatrimestre a través del Taller Virtual Red Norte Grande, en donde dentro de un marco claramente acotado y valiéndonos de un tema-problema planteado se trabajó en red con alumnos y profesores de diferentes facultades, provocando un incentivo que enriqueció el proceso, con las complicaciones esperadas y controladas, resultantes de los diferentes tiempos, retrasos en la devolución de las críticas, diferentes maneras de encarar el proceso, modos de representar y otros aspectos que hacen a la naturaleza del tipo de ejercicio encarado.

El trabajo realizado en estas condiciones nos permitió hacer un seguimiento e identificación de los programas utilizados por nuestros alumnos y por los alumnos de la Facultad de Arquitectura de Tucumán. Pudimos determinar que todavía están en una etapa básica en lo que respecta al manejo de la tecnología digital en el proceso de diseño; son pocos los programas que manejan y los utilizan de manera rudimentaria en la mayoría de los casos. Si le sumamos a esto el limitado nivel de representación gráfica tradicional, el panorama no es muy alentador, pero luego del cursado del cuatrimestre y considerando varios grupos de diferente nivel, pudimos observar un crecimiento en varios aspectos: generación y comunicación de

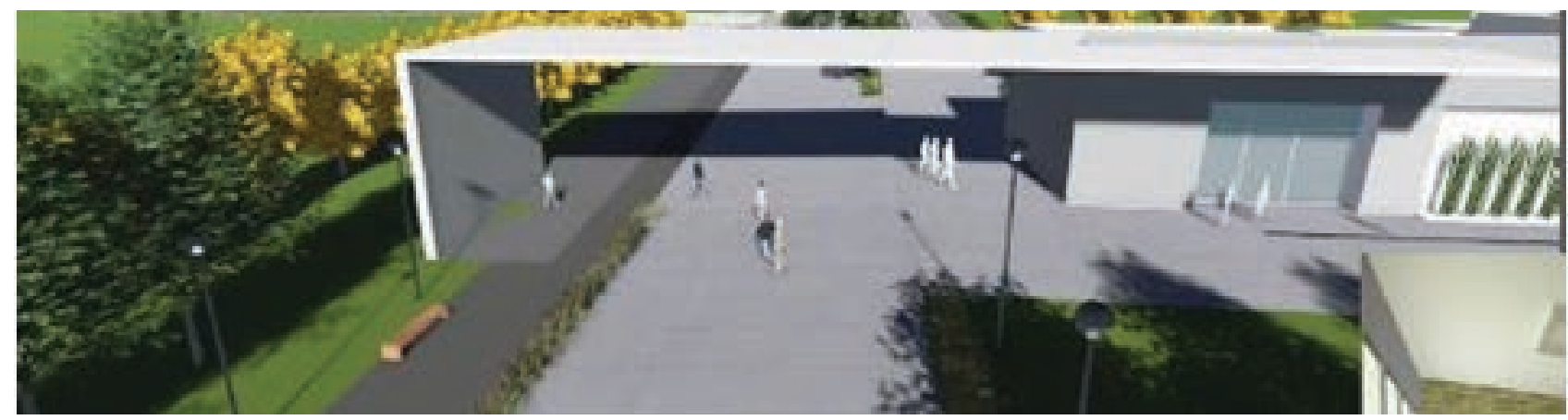



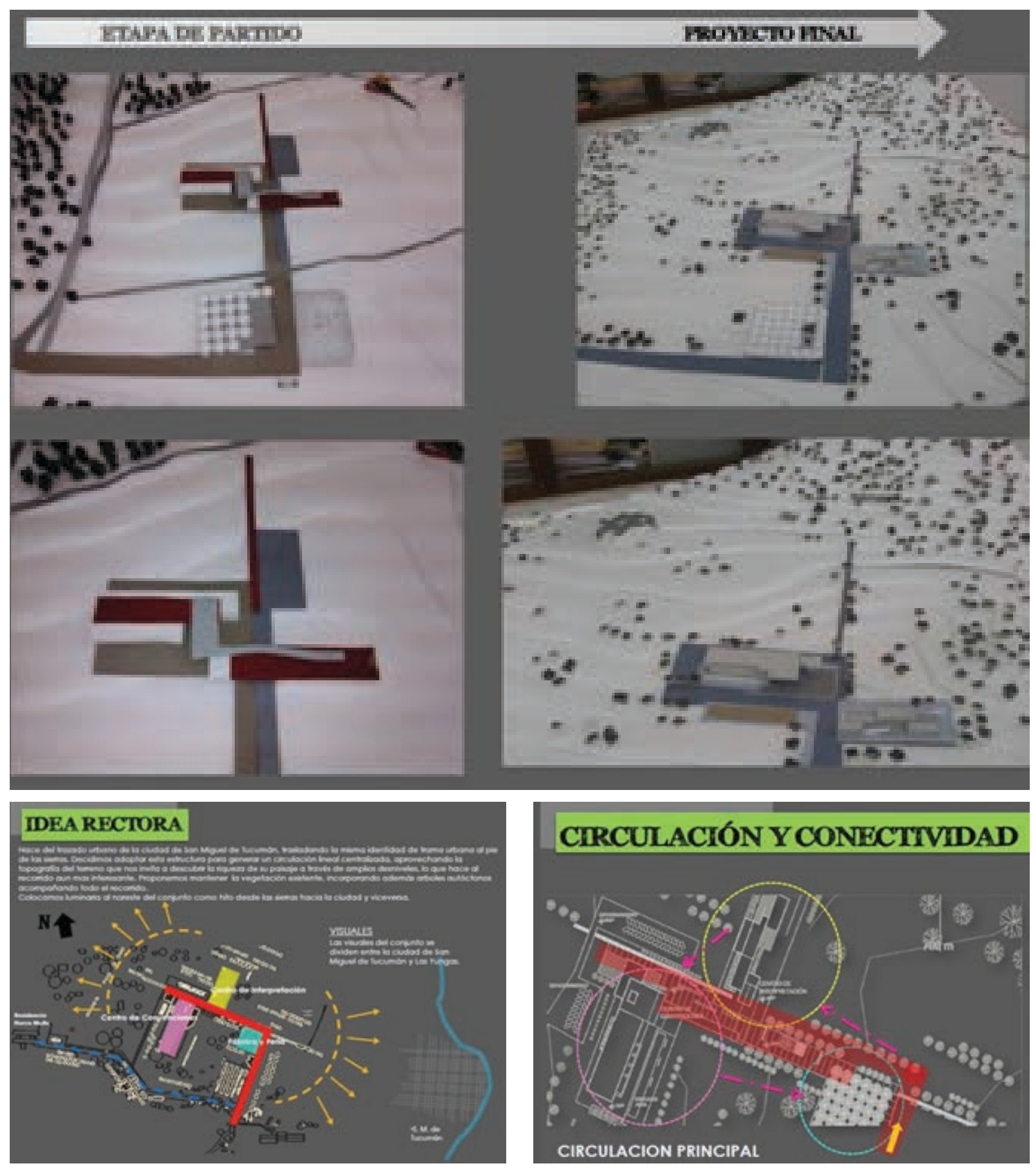

Etapa de anteproyecto, TP2, 2014. Alumos: Barrios Despo / De Langhe / Gómez

ideas, utilización de la maqueta y el fotomontaje, utilización de programas de edición, como el Photoshop, para el diseño de los paneles y láminas de presentación final (Arte Final) y el aprendizaje de la combinación de diferentes programas para lograr un buen resultado.

\section{Comisión arquitecta Gladis Pintos}

La arquitectura digital es un fenómeno reciente, que ha sido poco tratado en relación con las implicaciones de su representación gráfica. A partir del momento en que los proyectos son desarrollados con apoyo digital, aparece un universo de nuevas posibilidades formales, pero es destacable observar que la incorporación de estas nuevas tecnologías ha mantenido como uno de los ejes centrales de su operar la posibilidad de dialogar con los procesos más tradicionales.
En el caso de nuestros alumnos de Arquitectura IV, todavía desarrollan proyectos en los cuales los medios digitales son utilizados mayormente desde el punto de vista representacional, pero aún no han avanzado sobre propuestas arquitectónicas más experimentales, como la animación o el diseño tridimensional.

Analizando las representaciones arquitectónicas propuestas en cada etapa del proceso de diseño se devela que los alumnos interactúan con el uso de medios tradicionales en las primeras instancias de prefiguración (etapa de alternativas y partido), combinando con el uso intensivo de medios digitales en instancias de mayor definición (etapa de ajuste de partido, anteproyecto o proyecto). Queda sumamente evidenciado que nuestros alumnos, si bien manejan ciertos programas computacionales, aún no se insertan en explorar las opciones de 


\section{PANEL SÍNTESIS}

IOEA RECTORA:
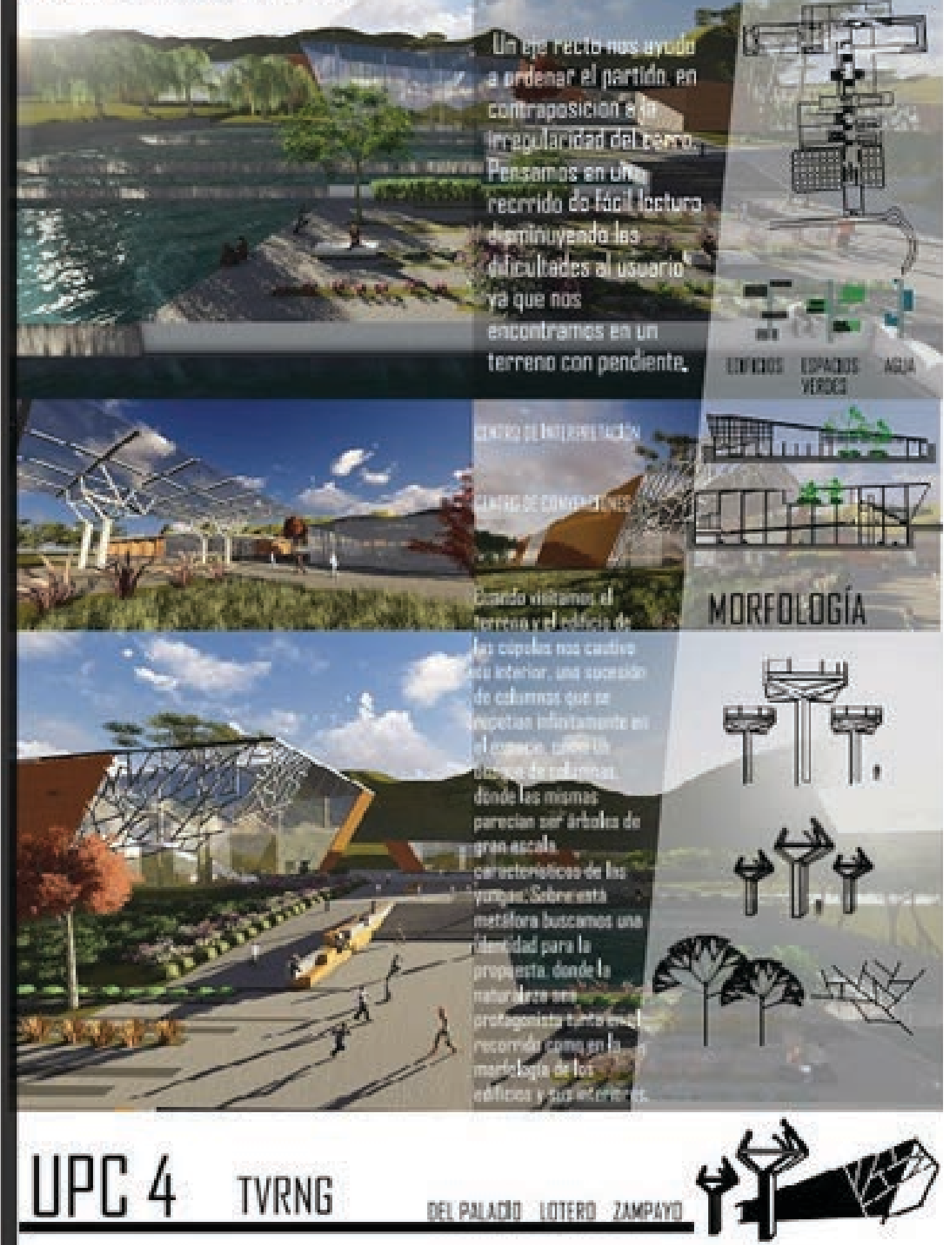

Póster final 2014. Grupo Del Palacio-Lotero-Zampayo

generar sus primeras ideas asistidos por programas tridimensionales o de animación. Aún estamos lejos de incursionar en esas experiencias, pero crecen cada año las posibilidades de representar en arquitectura.

Resulta indudable que cada vez más aceleradamente nuestros alumnos incorporan usos de medios digitales que les otorgan rapidez y además gran solvencia al defender sus propuestas. A mayor experiencia en el manejo de los sistemas informáticos, el futuro arquitecto pasa del dominio o conocimiento al desarrollo de destrezas y habilidades para interrelacionar todas las variables y posibles combinatorias que dan los software para hacer realidad su arquitectura. 
"La madurez proyectual del alumno solo se logra en esta relación constante de la práctica docente-alumno, a través de una comprensión mutua, y el docente debe motivar el aprendizaje del proyecto arquitectónico en un entorno virtual."

Los alumnos incursionan en actitudes arquitectónicas que interpretan las aportaciones de las tecnologías digitales para una experimentación de carácter más expresivo y formal, concediendo especial atención al tratamiento de las imágenes. Esto nos permitió observar un crecimiento interesante en varios aspectos de la representación: en la generación y comunicación de ideas, en la utilización de la maqueta y el fotomontaje y en la acertada utilización de programas de edición. El medio creativo en el taller Virtual está condicionado por los sistemas informáticos, estén actualizados o no, porque es el medio en el cual se desarrolla y produce la arquitectura. Es notable cómo se equiparan los niveles de producción y creación de los alumnos más experimentados en el uso de los programas computacionales y los menos experimentados a lo largo del proceso de diseño. En general, los alumnos no tienen temor a equivocarse en la aplicación de los programas, y la competencia con sus compañeros acelera el aprendizaje.

El taller virtual se manifiesta como un ámbito muy estimulante, donde los alumnos se ayudan de una u otra manera, y el docente influye en este comportamiento. La madurez proyectual del alumno solo se logra en esta relación constante de la práctica docente-alumno, a través de una comprensión mutua, y el docente debe motivar el aprendizaje del proyecto arquitectónico en un entorno virtual.

El taller virtual no solo favorece y optimiza la representación arquitectónica de las propuestas de diseño de nuestros alumnos, sino que se transforma en un ámbito poderoso de generación de conocimiento. Además, indudablemente el trabajo en red y colaborativo mejora no solo la representación de los proyectos, sino que incide en las acciones actitudinales de los alumnos, que bien estimulados afrontan cada vez con más solvencia los nuevos desafíos que implica el uso de los medios digitales.

\section{Comisión arquitecto Gustavo Tripaldi}

Cambios y mutaciones en los sistemas de representación

De la representación a la simulación: la variable ambiental de la arquitectura

En las últimas dos décadas se viene produciendo una serie de cambios y mutaciones en los procesos de enseñanza-aprendizaje que se desarrollan en los talleres de Arquitectura, gracias al vertiginoso avance de las tecnologías informáticas disponibles socialmente en la actualidad. Estos cambios, la mayoría de las veces no programados ni generados en las facultades de Arquitectura de los países no centrales (para no definirlos como periféricos) en materia de ciencia, tecnología en innovación, han afectado tanto a la comunidad de docentes-investigadores como a los propios alumnos, alterando las condiciones y modalidades que se repitieron durante varias décadas anteriores en materia de enseñanza de la arquitectura. Como toda innovación (en el sentido schumpeteriano), genera cambios irreversibles que se van consolidando en el tiempo, y en ocasiones prevalece lo pragmático sobrepasando en velocidad a los cambios curriculares que pueden ofrecer como respuesta las instituciones de enseñanza, sumando a esto la brecha tecnológica que afecta a nuestro país y la difícil situación para muchos docentes para obtener formaciones de excelencia en el nivel de posgrado, así como las escasas posibilidades de acceder a formar parte de grupos de investigación consolidados y con recursos de I+D+i en Arquitectura.

En el campo específico del tema que aborda la investigación desarrollada en el ciclo 2014, se presenta como recurrente el problema de las asimetrías según los grupos de estudiantes y según las etapas del proceso de diseño arquitectónico que analicemos. 


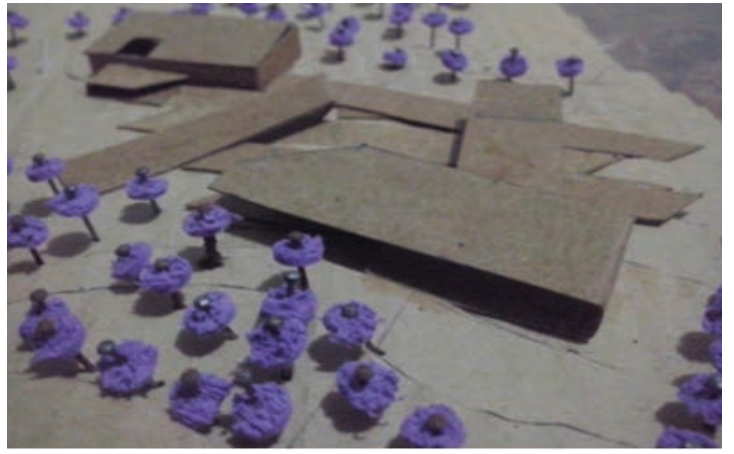

Código 12C006: proyecto de investigación

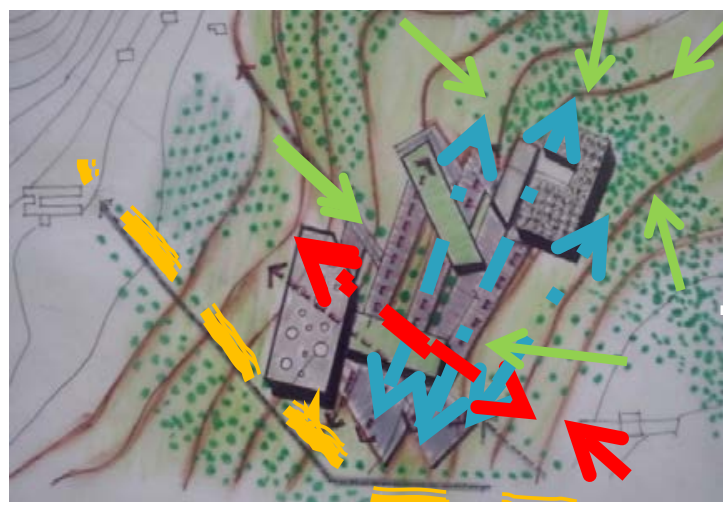

Se observan grupos de alumnos que comienzan a representar ideas e intenciones a mano alzada, que se pueden ver mediante ideogramas y croquis, y otros grupos que desde el inicio proyectual comienzan el proceso de ideas mediante las herramientas digitales, condicionados muchas veces por el mismo accionar de las herramientas, que los lleva a plantear ideas que no son respuestas totalizadoras del tema propuesto por la cátedra.

Esa instancia en que emerge la idea generadora - para así llegar a evolucionar para constituirse en un objeto arquitectónico de diseño- se desarrolla básicamente a mano alzada. Luego sí, se pueden verificar las ideas mediante herramientas digitales para mostrar en dos o en tres dimensiones, siempre en un principio de manera abstracta y simple. Este objeto-idea pasa a una nueva instancia superadora para ser desarrollada más en detalle; en ella aparecen nuevas herramientas, como los Renders, y esto sirve para explicar y hacer entender la propuesta arquitectónica, en la cual la materialización, la luz, la sombra, las texturas hacen al objeto. Se puede identificar que los alumnos que manejan la mano alzada como transmisión de sus ideas, como también aquellos que saben utilizar ciertas herramientas digitales son los equipos que proponen las ideas más potenciales, ideas y pensamientos que se transforman luego en imagen, en arquitectura.

Con respecto al trabajo en red que desarrolla la cátedra de Arquitectura IV, es indudable que esto se considera una gran herramienta motivadora del proceso, porque el alumno se encuentra prácticamente obligado a que sus ideas sean exhibidas en la red y a la vez a consideración de sus pares, como también de los docentes virtuales. Esta experiencia resulta muy enriquecedora, ya que ante un tema en común propuesto por la cátedra se pueden observar distintos puntos de vista, maneras particulares de leer una ciudad, un sitio, 

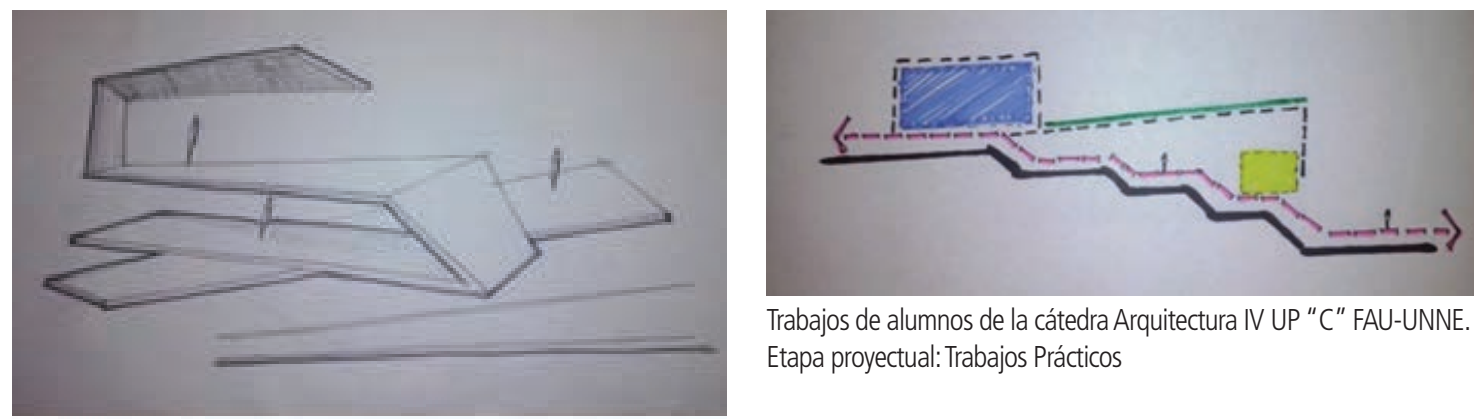

Trabajos de alumnos de la cátedra Arquitectura IV UP "C" FAU-UNNE. Etapa proyectual: Trabajos Prácticos
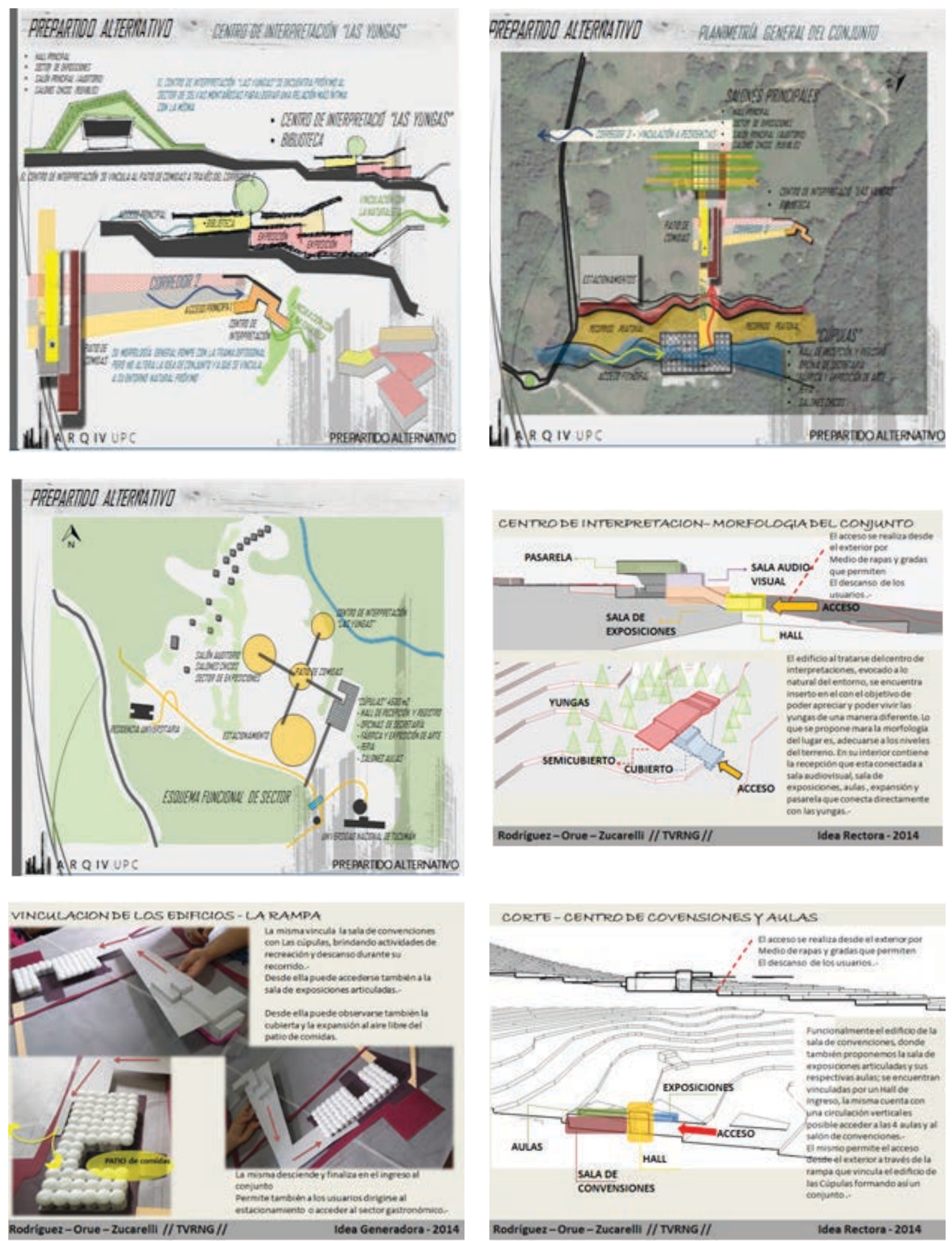
captar la cultura del lugar, etc. Versiones diferentes de ver, interpretar y hacer arquitectura, como también maneras diversas de comunicar ideas. Es este intercambio lo que provoca el enriquecimiento de esta experiencia virtual.

Además, este trabajo en red virtual obliga a los alumnos a repensar la manera de comunicar sus ideas en las distintas etapas del proceso proyectual, utilizando las herramientas adecuadas a tal fin, a los efectos de que las ideas sean entendidas y así poder evolucionar.

\section{CONCLUSIONES}

El rol que debe cumplir el taller de una Facultad de Arquitectura es el de una asignatura síntesis en la que tienen que aparecer rescatados los contenidos de las demás disciplinas, verificándose a través de la práctica concreta del hacer proyectual los conocimientos específicos de esos campos e interrelaciones, de manera creativa. Es necesario que dicha síntesis la realicen los alumnos, ya que la enseñanza implica ante todo dejar aprender. Coincidimos con DÍAZ BARRIGA en promover "el desarrollo de procesos de pensamiento, de formas de construcción de la información, lo que finalmente lleva a la elaboración de síntesis personales sobre procesos complejos". En la cátedra nos interesan las estrategias proyectuales, los procedimientos, la producción arquitectónica; tratamos de abarcar un espectro muy amplio, donde los alumnos puedan canalizar sus propias inquietudes arquitectónicas, y los ayudamos a que diseñen su propia estrategia, en un proceso sistemático y consciente. En todo momento el alumno debe ser consciente de qué está haciendo y por qué. Los proyectos de los alumnos tienen un fin pedagógico: deben ser ellos quienes elaboren sus puntos de partida y de llegada, y los docentes colaborar y verificar para que pueda cumplirse
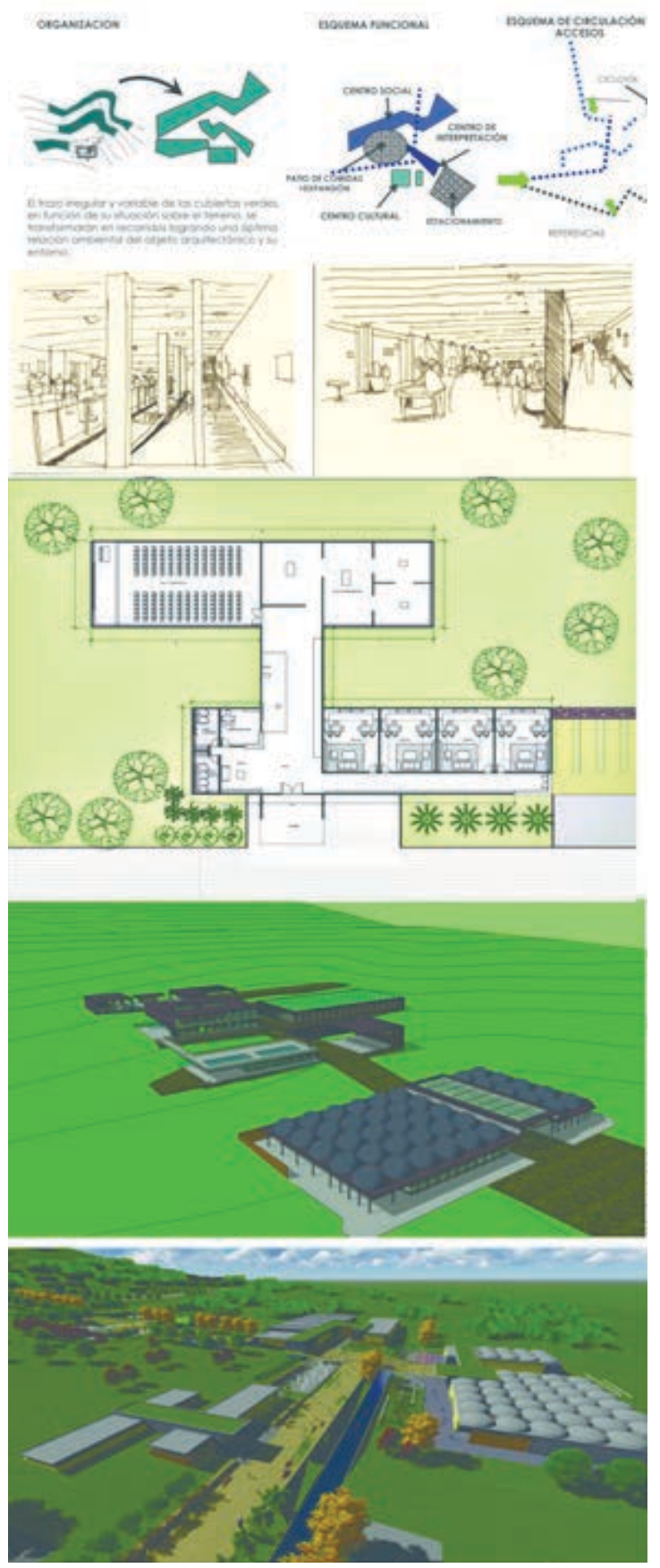

aquello que los primeros se propusieron, dentro del marco de los requerimientos dados por la cátedra.

En este contexto se han desarrollado observaciones participantes en el taller (investigación cualitativa), evaluando además las producciones de los alumnos, con la finalidad de tratar de entender cómo es que se da el aprendizaje del diseño arquitectónico hoy en día, sabiendo que la educación actual contempla conocimientos, actitudes y habilidades dentro de un mundo digital, y cómo impacta ese mundo en la representación arquitectónica.

Se han realizado observaciones para tratar de entender cómo es que los alumnos realizan la construcción de sus conocimientos en diseño arquitectónico utilizando herramientas para el diseño extraídas del mundo digital. En la 
actualidad, dentro del taller conviven el uso de herramientas antiguas y nuevas, se diseña en forma analógica (medios de representación tradicional) y de forma digital (representación gráfica mediante computadoras). Se ha detectado que los alumnos utilizan distintos programas para representar sus ideas, según las etapas del proceso de diseño en las que se encuentren. Las primeras instancias (más creativas) se fundamentan más en la "mano alzada", escaneando las producciones, y a medida que se avanza en la resolución el uso de ciertos programas digitales (por ejemplo, del Autocad) les confiere eficacia y rapidez.

El uso de la computadora ofrece a los alumnos un soporte fundamental a la hora de representar y comunicar sus ideas, y los más avezados en el manejo de los programas se desenvuelven con mayor celeridad y eficiencia. El aprendizaje del diseño arquitectónico es un problema complejo que involucra un sinnúmero de variables, pero es innegable que la computadora ha venido a facilitar este proceso introduciendo herramientas que auxilian y simplifican la construcción del nuevo conocimiento mejorando la comunicación de ideas arquitectónicas. El TVRNG, como taller en red, se expresa como un espacio donde se verifica la adecuada integración entre los recursos digitales y tradicionales.

En general se observó que el uso de la computadora ha venido a facilitar y potenciar la producción del alumno en la representación de las distintas etapas del proceso de diseño, y además el trabajo en un taller colaborativo propicia un ambiente de discusión e intercambio sumamente favorable, incentivador y optimizador, no solo en la formación del futuro arquitecto, sino además en la propia labor docente. En la experiencia 2014 el impacto del mundo digital en la enseñanzaaprendizaje del proceso de diseño arquitectónico es intenso, multidimensional y revolucionario, ya que aporta muchas ventajas no solo en cuanto a la representación arquitectónica, sino además en acercar el manejo de la información y trabajo en red, lo cual incide beneficiosamente en la producción del alumno. Se ha verificado en los trabajos de los alumnos que las herramientas del mundo digital motivan, favorecen y potencian el desarrollo del proceso de diseño arquitectónico, y a la vez se optimiza la interacción entre docentes y alumnos del taller de Arquitectura de cuarto año.

\section{BIBLIOGRAFÍA}

AMAYA, Blanca Lilia; ORFA BUITRAGO, Jerez (20015). "Educación personalizada, una modalidad educativa". Revista N. ${ }^{\circ}$ 26-www.utp.edu. $\mathrm{co/}$ chumanas/revistas/revistas/rev26/buitrago.htm. Recuperado el 5-7-2015. BLOOMER K. y MOORE Ch. (1982). Cuerpo, Memoria y Arquitectura. CAMPOS BAEZA, Alberto (2008) Aprendiendo a pensar. Ed. Nobuko. CAMPOS, Carlos (2012). Colección Nuevos Territorios en la Enseñanza de la Arquitectura. Ed. Nobuko.

CORONA MARTínEZ, Alfonso (1990) Ensayo sobre el Proyecto. CP67. Buenos Aires.

DELGADO YANES, Magalí y REDONDO DOMínGUEZ, Ernest (2007). Dibujo a mano alzada para arquitectos. Parramón, Barcelona.

DÍAZ BARRIGA ARCEO, Frida (1999) Estrategias docentes para un Aprendizaje Significativo. Ed. Trillas, México.

FACULTAD DE ARQUITECTURA, URBANISMO Y DISEÑO. Universidad Nacional de Córdoba. Julio de 2008. Antes de la Idea - Fábrica de Arquitectos.

FERNÁNDEZ, Roberto. El Proyecto Final. Univ. De La República, Montevideo, Uruguay.

KRAUEL, Jacobo (2010) Arquitectura Digital, Innovación y Diseño. Editorial Links.

LYNCH, Kevin (1980)"Planificación del Sitio". Ed. Gustavo Gilli, Barcelona. MINDEGUÍA MARTÍNEZ, Francisco. Qué investigación. http:// mindeguia.com/congresos/3IAU_M5_13.pdf. Recuperado el 5-7-2015. MONTAGU, A.; GROISMAN, M.; PIMENTEL, D. (2004) Cultura Digital. Comunicación y Sociedad. Ed. Paidós, Buenos Aires.

MOORE, Charles; ALLEN, Gerald (1976) Dimensiones de la Arquitectura. Gustavo Gilli, Barcelona.

PISCITELLi, Alejandro (2005) Internet la imprenta del SXXI. Ed. Gedisa SA, Barcelona.

SAINZ, J. (1990) El Dibujo en Arquitectura. Editorial Nerea, Madrid. SCHAPOSNIK, Viviana (2003) Arquitectura: investigación, teoría, proyecto. Ed. GeKa.

STENHOUSE, Lawrence (2004) La investigación como base de la enseñanza. Morata, Madrid.

TOGNERI, Jorge (1984) Polémica en la Arquitectura. Espacio Editora. WRIGHT, Frank Lloyd (1961) -CEPA- El Proceso Proyectual. Barcelona. 